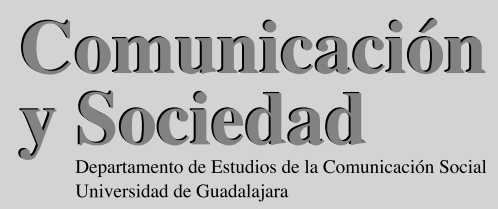

RESEÑA

\title{
Un futuro conectado: el estado de la cuestión
}

MERCEDES Miguel BORRÁS ${ }^{1}$

Vivimos un momento de enorme trascendencia, tecnológicamente hablando. El tercer milenio abrió las puertas hacia una nueva era digital que camina a pasos agigantados, llevándonos, cuando aún no se ha cumplido la primera década del nuevo siglo hacia el ciberes-
López Vidales, Nereida (ed.)

Medios de comunicación, tecnología y entretenimiento: un futuro conectado, Barcelona: Editorial Laertes, S.A. 2008, 260 pp.

pacio. Nos encontramos en una galaxia que no ha hecho sino poblar (y parece que empeñada hasta el infinito) la iconosfera enunciada por Gilbert Cohen-Seat allá por los años cincuenta del pasado siglo, y de la que Román Gubern señalaba su enorme trascendencia, contextualizándola tres décadas más tarde en "El simio informatizado": ecosistema cultural, basado en interacciones dinámicas entre diferentes medios de comunicación y entre estos y las audiencias, cuyos efectos eran potencialmente amenazadores para la asentada cultura gutenbergiana.

¿Cuáles son los efectos que la revolución digital está suponiendo en ese ecosistema cultural en la actualidad? Medios de comunicación, tecnología y entretenimiento: un futuro conectado parece responder a esta pregunta. Supone una valiosa aportación a los importantes cambios que se están produciendo en la comunicación audiovisual, los efectos sociológicos, las transformaciones sociales, culturales, de ocio, los modelos

1 Universidad de Valladolid, España.

Correo electrónico: mermiguel@eresmas.com 
de financiación y publicidad, etc. Difícil tarea la que emprende su editora, Nereida López Vidales, que valiéndose de su reconocida acreditación como profesora y periodista, pone todo su empeño en dejar constancia de esos importantes cambios que se llevan a cabo en la comunicación, y reúne a un elenco de profesionales del sector audiovisual y expertos en comunicación, junto a profesores e investigadores, todos ellos eruditos en la materia que analizan. Este acercamiento de la profesión a los ámbitos académicos, y viceversa, paradójicamente tan alejados, contribuye a dar una visión, en su conjunto, de un proceso imparable para situarnos ante el estado de la cuestión. Como certeramente afirma el escritor y periodista Diego Carcedo en el prólogo: "Creativos y programadores de contenidos deben hacer sus mejores aportaciones en ese mundo proyectado hacia el infinito que las nuevas tecnologías nos abren".

A lo largo de 14 capítulos, y guiados bajo una misma luz, se van desentrañando los efectos que la transformación digital está provocando en la comunicación (cambios profesionales, la espectacularización de la información, la tiranía de la audiencia, etc), dedicando especial atención a un hecho destacable y esperanzador, pues tras más de una década inmersos en esta era de la cibernética estamos pasando de la preocupación por la herramienta a los efectos que produce en la comunicación audiovisual.

Una ingente profusión de citas, referencias a congresos, foros de actualidad internacional y un apéndice al final del libro dejan constancia de las últimas aportaciones hechas por prestigiosos profesionales del sector. Un futuro prometedor el que se abre al lector en sus documentadas y rigurosas 250 páginas, "un futuro conectado".

En coherencia con su intención didáctica e informativa, el libro está organizado en tres partes, que muestran desde diferentes puntos de vista los efectos que está causando la revolución digital en la comunicación: en la primera parte, prensa, radio, televisión y cine informan y analizan el estado de la cuestión; la segunda, aborda la situación desde las audiencias y la tercera desde la industria.

El apagón analógico está previsto para el 3 de abril de 2010 y es indudable que la televisión es la gran protagonista, apunta Nereida López. Usuarios, operadores, profesionales, modifican el comportamiento y sus modelos de producción. Antonio Moral (subdirector de Contenidos Digitales de RTVE), añade que los cambios tecnológicos, aunque 
no modifican sustancialmente los objetivos de la televisión pública, sí obligan a reformular aspectos (digitalización conlleva más oferta de canales y servicios que atiendan todo tipo de audiencias). "Es necesario contextualizar la televisión pública como uno de los pilares fundamentales del estado del bienestar junto a la educación, la sanidad, la asistencia social". Un reto, pues, tecnológico y cultural generado por el nuevo panorama de convergencia multimedia como afirman Miguel A. Ortiz (director del Instituto Oficial de RTVE) y Santiago Gómez (profesor de programación de Radio y Televisión). La TDT (televisión digital terrestre), la televisión por teléfono móvil e Internet propician una sociedad multipantalla y está generando un nuevo escenario fragmentado que provoca un movimiento significativo de la audiencia y sus hábitos de consumo ("La televisión en familia ha muerto"). La televisión tiene dos nuevos competidores: la televisión en movilidad (teléfono móvil) y los videojuegos; estos últimos una realidad social sólidamente asentada, como señala Joaquín Pérez (director del Observatorio del Videojuego), y que están situados en las primeras posiciones del ocio juvenil. Va haciéndose necesario -o incluso "vital"- tener una formación en nuevas tecnologías para saber barajar conceptos relacionados con Internet.

La nueva frontera a la que se dirigen los medios de comunicación es Internet y el blog; es el cuaderno de bitácora de navegación, afirman los profesores Gotzón Toral y Jon Murelaga. ¿Cómo habilitar a la radio para responder con eficacia a estos retos? Lo que nos espera no es la técnica sino la interactividad que posibilita la tecnología: sacar lo mejor de la radio, es decir, la sencillez, la participación, la movilidad. Integrar los medios de comunicación en redes mediáticas por las que circulan textos escritos y visuales.

El reto, apunta la periodista Mariola Cubells, no es si desaparece el papel, sino que el periódico sea parte de una red de intercambio de información. La prensa gratuita, generadora de opinión, los Blogs (se crean 120 mil al día), democratizan pero también manipulan la información. Para ser periodista del siglo XXI, concluye, es necesario dominar las nuevas tecnologías.

¿Qué ocurre con la eclosión digital en el cine? Totalmente implantado el sistema digital, en el cine se da la paradoja, afirma Elena Medina, que sólo existe en algunas de las fases del proceso de producción (montaje y 
posproducción), y en rodaje y exhibición es todavía poco usual. El digital convivirá durante años con el negativo; el artista debe elegir el soporte que más se ajuste a sus necesidades, concluye Medina, haciendo gala de su doble condición de profesora y directora de documentales. En el cine de animación, Pilar Yébenes (profesora en la especialidad) señala que no tiene sentido, a estas alturas, plantearnos la guerra entre la animación tradicional o por ordenador $y$, al igual que Elena Medina, resta importancia a la técnica y aboga por las producciones digitales de animación como un todo en el que se incluyen las herencias tradicionales. Pone como ejemplo a Pixar que, además de generar tecnología, rompe con el modelo de cultura de elite y ha democratizado la era digital, lo mismo que ocurriera antaño con Disney, que fue "símbolo de ocio y negocio a escala mundial". Pero lo que es cierto, como apunta el productor y profesor Rafael Linares, es que los profesionales de la mercadotecnia están adoptando las tecnologías para gestionar y dar a conocer sus películas. Retos que deben ser asumidos por la industria y atender a los nuevos canales -Internet, telefonía móvil- de distribución y exhibición.

\section{DE LA ICONOSFERA AL CIBERESPACIO}

Internet ha subvertido la iconosfera, ese pacífico ecosistema en el que se movían televisión-radio-prensa. Producir en el nuevo escenario digital conlleva rapidez y abarata los costes en las infraestructuras. Los datos que aporta Antonio Castillo (director de la revista Producción Profesional) sobre las tendencias de futuro son reveladores: según un estudio de Datamonitor sobre inversiones en equipamiento en el mercado del broadcast, para 2012 el negocio crecerá en Estados Unidos y Europa hasta alcanzar 8,700 millones de dólares.

Mario Tascón opina que el cambio en las redes, la mayor potencia de los ordenadores y los equipos informáticos han trasformado la idea de Internet, un concepto fuertemente polisémico sobre el que hay muchos fenómenos asociados y en el que se inscriben los medios audiovisuales desarrollados en la red digital, los denominados cibermedios. Tascón, director de Prisacom (sociedad que gestiona Prisa en Internet), considera que es necesario incorporar ocio en la estructura de los contenidos de los cibermedios para lograr el éxito de esa futura red de redes. 
La opinión de los especialistas, recogida en los últimos foros y congresos, coincide una vez más en esta mirada atenta que envuelve al libro en su conjunto -la necesidad de atender a un mundo en constante transformación-, y pone el punto final sobre la situación actual y el futuro que nos espera.

Las diferentes voces, los enfoques, académico y profesional, confirman que Medios de comunicación, tecnología y entretenimiento: un futuro conectado ha logrado con creces el compromiso marcado por Nereida López Vidales: "señalar tendencias de futuro coherentes acerca del comportamiento, los usos, los contenidos, la financiación, la publicidad, los modelos de negocio, la convergencia tecno-digital". Obra, pues, de referencia obligada para profesores y estudiantes universitarios, pero también para los profesionales del sector audiovisual. No hay duda de que este texto multidisciplinar nos acerca al universo multimedia presente y se aventura en el que está por llegar. 